\title{
A INFLUÊNCIA DA RELAÇÃO PROFESSOR-ESTUDANTE NA APRENDIZAGEM DISCENTE: percepções de professores de Ciências e Matemática
}

\author{
Deise Nivia Reisdoeferl \\ Eliana Maria Mallmann Teixeira ${ }^{2}$ \\ Maurivan Güntzel Ramos 3
}

\section{RESUMO}

Este artigo tem por objetivo identificar e compreender as concepções de professores da área de Ciências da Natureza e Matemática acerca da influência da relação entre professor e estudantes sobre a aprendizagem. Foram coletados depoimentos de 17 professores integrantes de um Programa de Pós-Graduação na referida área. A Análise Textual Discursiva originou três resultados: a relação entre professor e estudante influencia na aprendizagem discente; as atitudes dos estudantes influenciam na sua aprendizagem; a atitudes do professor contribuem para a aprendizagem dos estudantes. Foi possível constatar que os participantes da investigação entendem que a afetividade e a boa relação entre professor e estudantes favorecem significativamente a aprendizagem dos estudantes. Os professores enfatizam a necessidade de atitudes dos estudantes como a confiança, a autodisciplina intelectual e o compromisso como favorecedoras da aprendizagem.

Palavras-chave: Relação professor-estudante. Afetividade. Aprendizagem em Ciências e Matemática.

\section{THE INFLUENCE OF THE RELATIONSHIP TEACHER-STUDENTS IN THE LEARNING:}

\section{perception of Science and Mathematics teachers}

\section{ABSTRACT}

This article aims at report the study whose objective is to identify and understand the conceptions of teachers in the area of Natural Sciences and Mathematics on the

\footnotetext{
1 Mestre em Educação (UEPG) e Doutoranda do Programa de Pós-Graduação em Educação em Ciências e Matemática (PUCRS). Professora do IFC-Campus Concórdia. Email: dnreisdoefer@hotmail.com

${ }^{2}$ Mestranda do Programa de Pós-Graduação em Educação em Ciências e Matemática (PUCRS). Professora da Rede Pública estadual do Rio Grande do Sul. E-mail: eliana.teixeira@acad.pucrs.br

3 Doutor em Educação (PUCRS) e Professor do Programa de Pós-Graduação em Educação em Ciências e Matemática (PUCRS).E-mail: mgramos@pucrs.br
} 
influence of the relationship between teacher and students on learning. We collected testimonies from 17 professors from the areas of Natural Sciences and Mathematics. All participants are enrolled in a Postgraduate Program in Science and Mathematics Education. The Discursive Textual Analysis brought about three results: the relationship between teacher and student influences student learning; Students' attitudes influence their learning; Teacher attitudes contribute to the student learning. It was possible to verify that the participants of the research understand that affectivity and the good relation between teacher and students significantly favor the learning of the students. As a result of the investigation, the teachers emphasize the need for the students to have attitudes as confidence, intellectual self-discipline, and commitment as facilitators of learning.

Keywords: Teacher-student relationship. Affectivity. Science and Mathematics Learning.

\section{LA INFLUENCIA DE LA RELACIÓN PROFESORES-ESTUDIANTES EN EL APRENDIZAJE: percepción de profesores de Ciencia y Matemática}

\section{RESUMEN}

Este artículo es el relato de un estudio con la intención de identificar y comprender las ideas de profesores de Ciencias Naturales y Matemáticas sobre la influencia de la relación entre el profesor y los alumnos sobre el aprendizaje. Testimonios de 17 profesores en las áreas de Ciencias Naturales y Matemáticas fueran obtenidos. Todos eran alumnos de uno programa de postgrado en Educación en Ciencias y Matemáticas. Para el tratamiento de las informaciones se utilizó el análisis textual discursivo. El análisis resultaron tres categorías: a relación entre profesor y estudiante influye en el aprendizaje discente; las actitudes de los estudiantes influyen en su aprendizaje; las actitudes del profesor contribuyen al aprendizaje de los estudiantes. Los participantes de la investigación entienden que la buena relación afectiva entre el profesor y los alumnos promueven significativamente el aprendizaje de los alumnos. Los profesores enfatizan la necesidad de actitudes de los estudiantes que pueden favorecer la relación con el profesor y con el aprendizaje.

Palabras clave: Relación profesor-estudiante. Afectividad. Aprendizaje en Ciencias y Matematicas.

\section{INTRODUÇÃO}

O tema central deste texto é o vínculo entre a relação professorestudantes e aprendizagem discente. Trata-se de estudo sobre esse tema na perspectiva de professores das áreas de Ciências da Natureza e Matemática. Assim, a problemática da pesquisa pode ser assim enunciada: Quais são as concepções de professores das áreas de Ciências da Natureza 
e Matemática, ingressantes em um Programa de Pós-Graduação em Educação em Ciências e Matemática, acerca da influência da relação entre professor e estudantes sobre a aprendizagem?

Para construir respostas a esse questionamento, foram coletados depoimentos de professores de Ciências e Matemática, os quais foram analisados por meio da Análise Textual Discursiva.

A investigação se justifica pela necessidade de se compreender o vínculo das relações interpessoais na sala de aula com aprendizagem, bem como promover reflexões sobre o assunto com vistas a qualificar essas relações.

Assim são apresentados os pressupostos teóricos sobre o tema, relacionando afetividade na relação entre professor e estudante. Após, são apresentados os procedimentos metodológicos empregados na investigação. Na sequência é apresentada a análise, na qual são discutidas teoricamente as categorias que emergiram das respostas dos participantes da pesquisa.

\section{PRESSUPOSTOS DA INVESTIGAÇÃO}

É comum observar que a relação professor-estudante permeia a indisciplina, o excesso de reclamações de ambos os lados e por vezes isso culmina com atos de indisciplina, violência e até mesmo falhas no aprendizado discente. Ou seja, o cotidiano de sala de aula está impregnado de divergências de ideias e diferentes ideais de comportamento. Por isso muito autores defendem a ideia de que é necessário propiciar na escola um espaço de interação e diálogo, de modo a favorecer um ambiente propício ao aprendizado, valorizando a divergência de ideias, a cooperação entre o trabalho realizado pelo professor e pelos alunos e acima de tudo, a valorização das relações humanas dos envolvidos no processo de ensino e aprendizagem.

Nesse sentido, Vygotsky (1998) dá fundamental importância para as 
interações sociais para o desenvolvimento e aprendizagem do sujeito e considera que o aprendizado deriva do processo de interações que ocorrem entre as pessoas.

Para Freire (1996), a partir de sua experiência na condição de aluno, o professor por vezes não imagina o que um simples gesto pode representar para o aluno o que para o docente é insignificante, pois tem uma força muito poderosa que pode contribuir significativamente para a formação do aluno. Com muita incerteza sobre as sua capacidade e insegurança sobre o que havia produzido, relata um fato que the ficou marcado, quando aguarda ansiosamente o resultado de sua avaliação por um professor considerado severo:

Em certo momento me chama e, olhando ou re-olhando o meu texto, sem dizer palavra, balança a cabeça numa demonstração de respeito e de consideração. O gesto do professor valeu mais do que a própria nota dez que atribuiu à minha redação. O gesto do professor me trazia uma confiança ainda obviamente desconfiada de que era possível trabalhar e produzir. De que era possível confiar em mim, mas que seria tão errado confiar além dos limites quanto errado estava sendo não confiar (FREIRE, 1996, p. 43).

A relação entre professor e aluno necessita fundar-se na superação da ideia de poder por parte do professor e de passividade por parte do estudante, como, frequentemente se observa em salas de aula.

É mais adequado à ideia de professores e estudantes serem parceiros de trabalho, como refere Demo (2007). Nesse sentido, é necessário valorizar o que os estudantes dizem, o que perguntam, o que querem fazer, o que querem aprender. Os estudantes devem ser respeitados e serem considerados sujeitos da aprendizagem, não objetos (lbid).

Os avanços na Educação são muito mais significativos se forem conduzidos por um viés da educação positiva do que pela repressão. De acordo com Moran (2014, p. 27) é "importante não começar pelos problemas, pelos erros, não começar pelo negativo, pelos limites. E sim pelo positivo, pelo incentivo, pela esperança, pelo apoio na capacidade de aprender e de mudar". Morales (1998) defende que, pela sua 
complexidade, a relação entre professor e estudantes não pode ser reduzida a fria relação didática, nem a uma relação humana calorosa. Entretanto, há que se ter equilíbrio nesse processo.

O professor, ao demostrar a relação de afeto pelos estudantes contribui para que eles se sintam mais seguros e aprendem com maior facilidade. De acordo com Morales (1998, p. 61) "a conduta do professor influi sobre a motivação, afetividade e a dedicação do aluno ao aprendizado". Assim, o professor ao reforçar a autoconfiança dos estudantes, contribui para manter uma atitude de respeito e cordialidade em sala de aula, que reverbera no meio social.

Nessa perspectiva, a emoção é manifestação do campo afetivo e expressão dos sentimentos. Conforme Chalita (2004), as emoções são essências para a aprendizagem e ressalta que o professor é um incentivador do estudante a se dedicar e buscar resultados significativos na aprendizagem. Para o autor: "O professor é a referência, é o modelo, é o exemplo a ser seguido e, exatamente por causa disso, o pouco que fizer afetuosamente, uma palavra, um gesto, será muito para o aluno com problemas" (Ibid, p. 153).

Assim, analisar e discutir as relações afetivas entre professores e estudantes, pressupõe o estabelecimento de concepções acerca do tema. A teoria do desenvolvimento cognitivo de Wallon (1978) mostra-se fundamental para a discussão sobre a relação entre os sujeitos, pois em seus estudos tentou demonstrar que existe uma estreita relação entre os aspectos afetivos, cognitivos e motores no processo de desenvolvimento humano.

Nesse sentido, Wallon (Ibid) declara que é impossível separar o biológico, o cognitivo e o afetivo, sendo que o desenvolvimento humano progride por meio das emoções e da relação com o meio. As relações estabelecidas no meio escolar, em especial a relação entre professor e estudante, podem ser consideradas como fundamentais para 0 desenvolvimento do estudante em todos os seus aspectos, em especial o cognitivo. 
Wallon afirma que a afetividade é a fonte do conhecimento, ou seja, a afetividade e a inteligência são inseparáveis na evolução psíquica. Para o autor a afetividade tem importante papel fundamental na formação da inteligência, pois determina interesses e necessidades individuais do indivíduo. "Atribui-se às emoções um papel primordial na formação da vida psíquica, um elo entre o social e o orgânico" (WALLON, 2008, p. 73).

A partir das ideias de Wallon, Ferreira e Acioly-Régnier (2010) definem afetividade como domínio funcional, o qual se manifesta de modos diversificados num processo de complexificação ao longo do desenvolvimento do indivíduo. Esse domínio emerge de uma base eminentemente orgânica até alcançar relações dinâmicas com a cognição, presente nos sentimentos.

Na concepção dos autores, a proposta educativa de Wallon deixa claro que tanto a escola como a relação professor-estudante são consideradas componentes fundamentais para que haja desenvolvimento completo do sujeito, ou seja, a integração é fator essencial na formação completa do educando. Assim, pensar a sala de aula, e as relações nela existentes, em especial a do professor com os seus alunos, implica ter a visão de que o aluno é uma pessoa completa e capaz de participar.

Contemporaneamente, a Neurociência tem contribuído para mostrar e valorizar as relações entre emoção, afeto e aprendizagem. Nesse sentido, de acordo com Cosenza e Guerra (2011), a amígdala é considerada o centro nervoso regulador dos processos emocionais. Para os autores, as emoções, manifestam-se por meio de alterações na sua fisiologia, mobilizando os recursos cognitivos existentes, em especial a atenção e a percepção. O córtex orbitofrontal é responsável pelo controle social das respostas emocionais e atua na associação entre os processamentos sentimentais e cognitivos ou racionais no cérebro. Por isso, a dimensão emocional deve ser levada em conta pelos educadores.

Cosenza e Guerra (Ibid), destacam a importância da emoção, pois controla os processos motivacionais. Nesse sentido, a motivação se 
manifesta em função da busca da satisfação ao se alcançar um objetivo. A motivação pode ser interna, como por exemplo, a fome, ou externa, como por exemplo, um desafio. Por sua vez, o processo de organização das ações, que visam a alcançar a satisfação, está fortemente ligado à aprendizagem. Entretanto, emoções como estresse e ansiedade prolongados podem ser prejudiciais ao processo de aprendizagem, pois liberam os hormônios glicocorticoides que podem vir a destruir neurônios do hipocampo.

Por tudo isso, as emoções precisam ser consideradas nos processos educacionais. Logo, é importante que o ambiente escolar seja planejado de forma a mobilizar as emoções positivas (entusiasmo, curiosidades, envolvimento, desafio), enquanto as negativas (ansiedade, apatia, medo, frustração) devem ser evitadas para que não perturbem a aprendizagem (COSENZA; GUERRA, 2011, p. 84).

Um ambiente escolar no qual o estudante se sinta seguro, estimulado e valorizado pode promover emoções positivas. Entretanto, as emoções podem ter origem em outras fontes como, por exemplo, no contexto familiar ou social. Nesse caso, o professor pode orientar o estudante a lidar de forma adequada com os sentimentos, o que pode contribuir para o aprendizado e desenvolver no sujeito uma maior capacidade de viver harmoniosamente em sociedade.

Diante dessas considerações e da interlocução teórica procedida, observa-se que a relação professor-estudantes é complexa, mas deve ser uma relação dinâmica que envolva a interação de ambos, incluindo as suas condições de vida, sua relação com a escola, a percepção de si mesmo e do outro e a compreensão do conhecimento objeto de estudo.

\section{PROCEDIMENTOS METODOLÓGICOS}

Relembrando a proposta da investigação, a intenção é identificar e compreender as concepções de professores da área de Ciências da Natureza e Matemática, ingressantes em um Programa de Pós-Graduação em Educação em Ciências e Matemática, acerca da influência da relação entre professor e estudantes sobre a aprendizagem. Para isso, foram 
coletados e analisados depoimentos de 17 participantes da pesquisa sobre essas concepções.

Os participantes da investigação são professores nas áreas de Química, Física, Biologia, Ciências e Matemática, ingressantes no Programa de Pós-graduação em Educação em Ciências e Matemática de uma universidade comunitária do Rio Grande do Sul, Brasil. Todos esses participantes são licenciados em Biologia, Física, Matemática e Química, portanto, professores das áreas de Ciências da Natureza e Matemática. Dos 17 participantes, 10 cursaram pós-graduação lato sensu (especialização), nas áreas de Educação inclusiva, Biopsicologia, Informática na Educação, Geometria, Remaniana e Topologia, Ensino da Matemática, Pedagogia Gestora, Administração Superior, Orientação Escolar, Metodologia em Ed. Matemática, Informática na Educação, Biomedicina, Educação Infantil, Metodologia de Ensino de Ciências da Natureza. Dois ingressantes em curso do doutorado são mestres em Matemática Pura e em Educação. Assim, em relação à formação, é um grupo de participantes que, em sua maioria, tem uma formação além da graduação (licenciatura), evidenciando interesse em avançar e aperfeiçoar-se no campo da docência.

Dos 17 participantes, apenas dois não atuavam na docência na época da pesquisa. 11 professores (64,7\%) atuavam na Educação Básica, três $(17,6 \%)$ no Ensino Superior e um $(5,9 \%)$ atuava nos dois níveis. Os que atuavam na Educação básica estavam inseridos nas redes municipal, estadual, federal ou privada. O tempo de atuação no magistério destes participantes situava-se entre um e 27 anos, com média de 11 anos. A carga horária semanal de docência ficava entre 10 e 44 horas, com média de 26 horas. As idades dos participantes variavam entre 21 e 59 anos, com média de 34 anos.

Essas informações mostram, em geral, um grupo jovem, com formação em nível lato sensu e intenso envolvimento profissional no campo da docência, predominando na Educação Básica.

Com vistas a construir possíveis respostas ao problema de pesquisa, os 
participantes responderam a um questionário, sendo que a pergunta analisada neste artigo é a seguinte: Como a relação entre professor e estudantes influencia na aprendizagem dos estudantes em Ciências e Matemática?

A investigação tem abordagem qualitativa, pois, na perspectiva de Bogdan e Biklen (1994), compreende a produção de informações descritivas, que são obtidas por meio de relação direta do pesquisador com o contexto e as circunstâncias sob investigação.

Para Minayo (1994), a pesquisa qualitativa propõe-se a responder questões muito particulares, preocupando-se com um nível de realidade não passível de ser quantificado. Ou seja, a pesquisa qualitativa atua em um universo que envolve crenças, significados, valores e atitudes, "[...] o que corresponde a um espaço mais profundo das relações, dos processos e dos fenômenos que não podem ser reduzidos à operacionalização de variáveis" (lbid, p. 21).

É também naturalística, pois, como concebem Lüdke e André (2013), a investigação se desenvolve numa situação natural, com uma riqueza de dados descritivos. Além disso, a investigação focaliza a realidade de modo complexo e contextualizada.

Além de ser qualitativa e naturalística, a investigação é fenomenológico-compreensiva, pois está voltada à compreensão de fenômenos da realidade. Nesse sentido, a fenomenologia envolve situações nas quais a verdade se manifesta em forma de essências do fenômeno, que precisam ser atingidas por intuição (MERLEAU-PONTY, 1999), sendo um processo auto-organizado.

Ghedin e Franco (2011, p. 104) justificam a dificuldade da interpretação dos fenômenos que envolvem educação, ao afirmar:

O fenômeno educativo não é facilmente apreendido, quer pela expansão, flexibilidade, variabilidade, porosidade de seu acontecer existencial, quer pela incapacidade dos métodos e técnicas da ciência tradicional em captar toda dimensão e potencialidade desse objeto tão mutante, tão metamórfico, carregado de valores, de intencionalidades e de projetos implícitos. 
Portanto, esta investigação não teve o objetivo de prever um resultado, o que denotaria uma ação de natureza positivista ou empíricoanalítica. A intenção era compreender as ações e modos de pensar dos participantes. Como afirma Heidegger (2000), a linguagem é a alma do ser. Nesse sentido, a fenomenologia valoriza a linguagem como modo de expressão dos fenômenos de forma intensa, pois não serve apenas para comunicar novas compreensões uma vez atingidas, mas como modo de acesso aos fenômenos e às suas essências. A linguagem possibilita a impregnação nos fenômenos. Por isso, essa abordagem também se aproxima do paradigma interpretativo-hermenêutico (HABERMAS, 2014) de produção do conhecimento, considerando os princípios da hermenêutica apontados por Gadamer (2008).

Como estratégia, a pesquisa é entendida como um estudo de caso. Lüdke e André (2012) compreendem que esse tipo de estudo atende a interesses do pesquisador em explorar algo particular, que apresenta valor em si próprio. O estudo de caso, na perspectiva de Yin (2010), envolve o estudo de uma situação dentro de um ambiente ou contexto contemporâneo da vida real delimitado pelo tempo e lugar. Denzin e Lincoln (2012) entendem que o estudo de caso é uma estratégia de pesquisa.

Desse modo, optou-se por caracterizar esta investigação como abordagem qualitativa, fenomenológico-compreensiva por meio do estudo de um caso, envolvendo professores das áreas de Ciências e Matemática, ingressantes em um curso de Pós-Graduação em Educação em Ciências e Matemática, para compreender seu modo de pensar a influência da relação entre professor e estudantes na aprendizagem.

Para análise dos depoimentos dos participantes, utilizou-se a Análise Textual Discursiva - ATD (MORAES; GALIAZZI, 2013), que se apresenta coerente com os referenciais que embasam a pesquisa, favorecendo a sistematização do processo de análise e interpretação do conhecimento dos professores envolvidos nessa investigação. A ATD é compreendida como 
[...] um processo auto-organizado de construção de compreensão em que novos entendimentos emergem de uma sequência recursiva de três componentes: desconstrução, a unitarização, o estabelecimento de relações entre os elementos unitários, a categorização, e o captar do novo emergente em que nova compreensão é comunicada e validada (Ibid, p. 192).

Desse modo, de acordo com os autores, o processo de análise consiste em três movimentos: a unitarização; a categorização; e a construção de metatextos. A unitarização consiste na desmontagem dos textos produzidos pelos participantes (unidades de análise, que compõem o corpus da investigação) ao responderem o questionário, originando unidades de sentido. É necessário codificar as unidades de sentido com vistas a poder-se retornar aos depoimentos caso seja necessário.

Após obterem-se as unidades de sentido, é necessário nomeá-las, isto é, escrever um título que, de modo sintético, expresse o que está dito. Assim, no processo de unitarização e ao nomear as unidades de sentido, já se inicia o movimento de interpretação. Esse movimento é importante para que o pesquisador vá se impregnando com as informações, o que contribui para que o fenômeno se manifeste.

Posterior a obtenção das unidades, inicia-se o processo de categorização, que consiste em reunir as unidades de sentido com significados próximos. Esses significados vão sendo percebidos pelo pesquisador, de modo que ocorra a emergência das categorias. Isso significa que se está trabalhando com categorias emergentes, não a priori.

Em uma primeira organização, surgem as categorias iniciais, geralmente em grande número. Após, se estuda a possibilidade de reorganizar essas categorias em um número menor, resultando nas categorias intermediárias. Essas são novamente reagrupadas em um número menor de categorias finais.

Esse processo é bastante importante, pois além de favorecer a impregnação do pesquisador e a emergência das categorias, essas são muito uteis na organização do texto. É necessário lembrar que essa análise 
tem por meta desconstruir os depoimentos dos participantes da pesquisa e reconstruí-lo, em um novo texto, de modo que se obtenha a "compreensão renovada do todo" (MORAES; GALIAZZI, 2013, p. 12).

Para finalizar a análise, elaboram-se metatextos, que consistem em textos analíticos, descritivos e interpretativos para cada categoria final.

Para os autores, o metatexto corresponde à concretização de todas as etapas da ATD.

A análise textual discursiva visa à construção de metatextos analíticos que expressam os sentidos lidos num contexto. A estrutura textual é constituída por meio de categorias e subcategorias resultantes da análise. Os metatextos são constituídos de descrição e interpretação, representando o conjunto um modo de teorização sobre os fenômenos investigados (ibid., p. 32).

Nesse processo, tenta-se captar o novo emergente. Esta é a etapa em que o pesquisador expõe suas intenções e novos entendimentos a partir de uma análise rigorosa dos dados realizada. A confiabilidade dos resultados de uma análise, para os autores depende do rigor com que cada etapa foram desenvolvidas e a análise foi construída (lbid). Nesse caso, espera-se do pesquisador a consciência de que, por ser uma interpretação, o resultado é sempre inesperado: "os resultados finais, criativos e originais, não podem ser previstos" (Ibid, p. 12).

Na ATD, a intensidade com que o pesquisador se envolve no processo de análise é responsável pela qualidade e originalidade das compreensões renovadas que se apresentam. Tais qualidades dependem ainda das pressuposições teóricas e epistemológicas assumidas pelo pesquisador ao longo de sua investigação, sempre associada ao problema de pesquisa - o que se está procurando ou tentando responder.

\section{ANÁLISES E DISCUSSÕES}

Por meio das análises das respostas apresentadas pelos participantes, foi possivel estabelecer, pela emergência, três categorias principais: a relação entre professor e estudante e a influência da afetividade como 
contribuição para a aprendizagem discente; as atitudes dos estudantes como fatores de influência na própria aprendizagem; a influência das atitudes do professor na relação com os estudantes e sua contribuição para a aprendizagem.

$\mathrm{Na}$ sequência são analisadas e discutidas as categorias que emergiram a partir das respostas dos participantes. É importante destacar que os participantes são nomeados ficticiamente como Professor, seguido de uma letra para garantir 0 anonimato. Também, se destaca que os enunciados literais dos participantes são expressos em itálico para diferenciar das citações literais de autores.

\section{A relação entre professor e estudante influencia na aprendizagem discente}

Em relação a essa categoria, são consideradas algumas ideias principais, que emergiram a partir das respostas dos participantes, nas quais a afetividade é enaltecida por meio das relações de respeito, da reciprocidade e da construção do conhecimento nas relações entre professor e estudante.

Dessa forma, foi possível perceber que, na opinião dos professores, as relações de respeito surgem como fator determinante nas relações entre professor e estudantes para que ocorra aprendizagem dos estudantes.

Essa afirmação pode ser evidenciada a partir dos enunciados de três dos participantes. O Professor C, afirma que "A relação professor-estudantes influencia diretamente na aprendizagem. Quando os estudantes gostam de seu professor e sabem que seu professor também gosta deles, aprendem melhor [...]". Nesse sentido o Professor F também afirma que "A relação professor-estudantes influencia fortemente na aprendizagem por trazer elementos como confiança, valorização, respeito e afetividade". E o enunciado do Professor $N$ também evidencia a relação de respeito: "A relação entre professor e estudantes é importante que seja mutuamente cordial e afetiva, ou seja, ambas as partes envolvidas devem, 
primeiramente, respeitarem-se e manterem uma relação amigável".

Esses enunciados são corroborados por Vygotsky (1994), que frisa a importância das interações sociais, afirmando que a construção do conhecimento ocorre a partir de um grande e importante processo de interação. Destaca o autor, além da importância da socialização no processo de construção do conhecimento, que a afetividade tem um importante papel na construção do próprio sujeito, em suas ações.

Para Wallon (1998, p. 15),

[...] o processo de evolução depende tanto da capacidade biológica do sujeito quanto do ambiente, que o afeta de alguma forma. Ele nasce com um equipamento orgânico, que lhe dá determinados recursos, mas é o meio que vai permitir que essas potencialidades se desenvolvam.

Dessa forma, o aprender na perspectiva dialógica, "é mais que uma relação de saber; é relação de existência de vida; aprender é uma modificação estrutural não do comportamento, mas da convivência" (MATURANA, 1998, p. 29).

Nesse sentido, Libâneo (1994, p. 249) ressalta que fazem parte da organização e das condições do trabalho docente "as relações entre professores e alunos, as formas de comunicação, os aspectos afetivos e emocionais, a dinâmica das manifestações na sala de aula [...]".

É nessa perspectiva que afirma o Professor K:

É importante que a relação e a interação do professor com os estudantes se dê de forma harmoniosa para que ocorra com sucesso o processo de aprendizagem. O diálogo e a afetividade são importantes para uma aprendizagem significativa.

Percebe-se que essa concepção está de acordo com as abordagens de Freire (2005), que considera sobremaneira a valorização do diálogo como importante meio de constituição dos sujeitos:

[...] o diálogo é uma exigência existencial. E, se ele é o encontro em que se solidarizam o refletir e o agir de seus sujeitos endereçados ao mundo a ser transformado e humanizado, não pode reduzir-se a um 
ato de depositar ideias de um sujeito no outro, nem tampouco tornar-se simples troca de ideias a serem consumidas pelos permultantes (FREIRE, 2005, p. 91).

Nesse enunciado, o que refere Freire pode ser interpretado como uma oposição à mera transmissão de ideias ou conhecimentos, por exemplo, pelo professor sobre os estudantes para serem consumidos, sem a devida possibilidade de reflexão e reconstrução. Isso se opõe ao processo de humanização.

Por meio das análises, foi possível compreender que a afetividade entre professor e aluno também contribui para a construção do conhecimento, conforme evidencia o Professor $\mathrm{N}$ :

Uma relação saudável entre professor e estudante é capaz de motivar o educando em participar e se envolver nas aulas, além disso, à medida que eles são parceiros de trabalho, juntos eles almejam a construção e reconstrução do conhecimento. Assim, uma relação positiva faz com que professor e estudantes se sintam bem uns na companhia dos outros. Portanto, quando docentes e discentes estão em sintonia, a aprendizagem é favorecida, pois todos estão interessados e motivados em aprender.

Da mesma forma o Professor K considera que:

É importante que a relação e a interação do professor com os estudantes se dê de forma harmoniosa para que ocorra com sucesso o processo de aprendizagem. O estudante se sente mais confiante em formular perguntas quando percebe que o professor é um sujeito que está ali para ajudá-lo a construir seu conhecimento e não apenas em depositar seu saber.

É possivel estabelecer uma aproximação entre as afirmações dos Professores N e K com as ideias de Freire $(2005, \mathrm{p} .18)$, ao afirmar que "O processo de ensino-aprendizagem envolve uma interação sócioafetiva entre um ensinante (aquele que ensina) e um aprendente (aquele que aprende)".

Essa afirmação de Freire, todavia, deixa a abertura para a ideia de que ensinantes e aprendentes não são, necessariamente nessa ordem, professores e estudantes. Em um ambiente de diálogo, o estudante pode ser ensinante também e o professor pode ser aprendente.

Os participantes também destacam que, em relação á afetividade, a 
reciprocidade nas relações entre professor e estudante é um fator que influencia a aprendizagem. Sobre isso, o Professor $F$ afirma que a "[...] afetividade pode ser determinante nesta relação, visto que a empatia leva ao comprometimento mútuo" e o Professor M refere que "essa relação deve ser uma via de mão dupla, o professor também tem de ser conhecido pelo estudante para que haja um diálogo (falem a mesma língua)".

Por sua vez, o Professor L afirma:

Outro fator está em promover um clima harmonioso em sala de aula para que os alunos sejam mais receptivos e interessados às atividades propostas. O professor que impõe respeito e, ao mesmo tempo, se mostra nivelado a seus alunos (desfazendo aquele pedestal imaginário na frente do quadro negro), consegue aproximá-lo dele, tornando a aula mais leve e descontraída.

Percebe-se nesses enunciados uma relação entre afetividade, empatia, harmonia, interesse, semelhanças de relações de poder, diálogo, comprometimento mútuo. Há uma complexidade nessas relações, mas os participantes professores mencionam a necessidade de considerar esses elementos para qualificar as aprendizagens em sala de aula. Isso está relacionado com o que afirma Morales (1998, p.49): A relação professoraluno na sala de aula é complexa e abarca vários aspectos; [...] é preciso ver a globalidade da relação professor-aluno mediante um modelo simples relacionado diretamente com a motivação [...].

Fica evidente a necessidade de estreitar a relação e o afeto entre professores e estudantes no ambiente escolar. Para isso, é "importante descobrir ações, estratégias, procedimentos sistêmicos e reflexões integradoras que estabeleçam vínculos fortes entre o aluno, o professor e o aprendizado" (ANTUNES, 2007, P.12).

Assim é possível perceber que, para os participantes da pesquisa, em todo o relacionamento deve haver afeto, sendo este o principal componente nas relações humanas. Fica evidenciado que, deve haver uma relação harmoniosa e em clima de parceria, de diálogo e de respeito e que cada um dos envolvidos nesta relação, reconheça as suas limitações e possibilidades. 


\section{As atitudes dos estudantes influenciam na sua aprendizagem}

Nesta categoria são evidenciados elementos associados às atitudes dos estudantes como fatores que influenciam a sua aprendizagem, na perspectiva dos professores, participantes da pesquisa. Entre essas atitudes, podem-se referir a confiança no professor, a afinidade com a disciplina, o compromisso com as aulas e a permanente busca de consciência das próprias dificuldades.

Em relação à importância da confiança no professor e nas relações, os professores $\mathrm{B}, \mathrm{F}$ e O afirmam:

A afetividade cria um bom ambiente de sala de aula, onde o estudante sente-se confortável com o professor, onde ele sabe que será respeitado independente das suas dificuldades (Professor B).

A confiança no professor traz ao estudante segurança, ingrediente fundamental para confiar-lhe a orientação para seu crescimento intelectual (Professor F).

Quando o aluno sente confiança no professor e sabe que este só quer the ajudar, ele se sente mais propício a perguntar quando tem dúvida, sem temer pelas críticas, mesmo se houver, porque sabe que está sendo assistido por alguém que quer sua evolução (Professor O).

Esses enunciados informam que, para que se estabeleça um vínculo entre o professor e os estudantes, é necessária a confiança no professor, o que se depreende que esse vínculo influencia na aprendizagem. Sobre isso, afirma Fernandez (1990, p. 52): "Não aprendemos de qualquer um, aprendemos daquele a quem outorgamos confiança e direito de ensinar".

Outra atitude necessária dos estudantes para o sucesso da relação professor-estudante, de modo a repercutir na aprendizagem, na percepção dos professores, consiste na afinidade com a disciplina. Essa afirmação pode ser exemplificada pela afirmação do Professor D, ao afirmar que "o professor é o principal condutor desta relação, pois o estudante pode até não ter certa afinidade com a disciplina, mas se o professor conseguir tocar afetivamente esse estudante, tudo ficará mais fácil". Sobre a afinidade com o professor, e consequentemente com a disciplina, o Professor B defende 
que: "a relação entre o professor e estudante tem capacidade de modificar (positivamente ou negativamente) a maneira como o estudante encara a disciplina de Ciências".

Desse modo, é possivel considerar que ensinar e aprender são práticas afetivas e reflexivas. A afetividade no aprender é de suma importância conforme afirma Morin (2002, p. 20): "[...] no mundo humano, o desenvolvimento da inteligência é inseparável do mundo da afetividade [...]", ou seja, a inteligência e a afetividade estão interligadas, como continua o autor:

[...] a afetividade pode asfixiar o conhecimento, mas pode também fortalecê-lo. Há estreita ligação entre inteligência e afetividade: a faculdade de raciocinar pode ser diminuída, ou mesmo destruída, pelo déficit de emoção; o enfraquecimento da capacidade de reagir emocionalmente pode mesmo estar na raiz de comportamentos irracionais (Ibid, p. 20).

Portanto, gostar do que se faz é importante para que ocorra um envolvimento no estudo e trabalho. Nesse sentido, ter afeto com a disciplina, significa que a disciplina afeta o estudante e, portanto, é provável que influa em sua aprendizagem.

Também foi mencionado nos depoimentos dos participantes que a relação entre professor e alunos afeta a atitude do estudante em comprometer-se com a disciplina, tendo, por consequência influência na sua aprendizagem. Isso se manifesta nos enunciados dos professores E e F, a seguir.

Os estudantes, quando gostam de seu professor, sentem-se valorizados por ele, tem a oportunidade de fazer descobertas e participar ativamente das aulas, se interessam mais pelo conteúdo estudado e consequentemente aprendem melhor (Professor E).

É fundamental que o estudante se sinta valorizado e respeitado pelo professor para que tenha a coragem de arriscar, tentar, errar, ou seja, para que vivencie, sem reservas, o processo de aprendizagem. A afetividade pode ser determinante nesta relação, visto que a empatia leva ao comprometimento (Professor F).

Nesse sentido, Vygotsky (2003) menciona que é a qualidade da relação afetiva que confere motivação do educando relação ao objeto de 
conhecimento, que, a partir das experiências vividas, desenvolve a autonomia e fortalece a confiança nas suas capacidades e decisões.

Também está manifesta nas respostas dos participantes a importância da relação entre professor e estudantes como modo de buscar consciência sobre suas dificuldades, o que pode originar curiosidade e vontade de aprender. Essa ideia está presente nos enunciados dos professores $B$ e $P$, apresentadas a seguir.

[...] o estudante sente-se confortável com o professor, onde ele sabe que será respeitado independente das suas dificuldades. Em um ambiente favorável para a aprendizagem o estudante consegue entender que ele é sujeito, e entende que o professor tem função de auxiliá-lo no seu caminho, e não reprová-lo (Professor B).

Quando o aluno sente confiança no professor e sabe que este só quer lhe ajudar, ele se sente mais propício a perguntar quando tem dúvida, sem temer pelas críticas, mesmo se houver, porque sabe que está sendo assistido por alguém que quer sua evolução (Professor P).

O fato de o estudante ver-se como alguém que é capaz de aprender é necessário para avançar em seus estudos. Freire (2005) acredita que o processo de aprender pode deflagrar no estudante uma curiosidade crescente, que pode leva-lo ao processo de criação.

Assim, é possível perceber no que afirmam os professores, participantes da investigação, que as atitudes dos estudantes em construir confiança no professor têm forte vínculo com a aprendizagem. Isso fica evidente nas afirmações de que os estudantes mantêm relações consigo mesmo, na medida em que se percebem sujeito do processo de aprender, e nas relações que se estabelecem com o professor, podendo transformar 0 ambiente escolar em um espaço acolhedor, no qual todos possam participar, expressar suas dúvidas e buscar respostas.

\section{As atitudes do professor contribuem para a aprendizagem dos estudantes}

Nesta categoria, foi possível analisar as respostas dos participantes sobre a importância das atitudes do professor na relação com os estudantes, que apontam para o uso de métodos e recursos adequados, bem como a necessidade de conhecer a realidade do estudante como fatores 
importantes para a aprendizagem dos estudantes. Dos depoimentos dos participantes, nesta categoria, depreende-se que a atitude do professor de usar métodos e recursos favoráveis à aprendizagem dos estudantes favorece a boa relação entre ambos no ambiente da sala de aula.

Em relação ao uso de métodos adequados e motivadores, o Professor $\mathrm{H}$ afirma que: "O uso de metodologias motivadoras, objetivos claros e o uso de novas tecnologias sem dúvida irá proporcionar momento de melhor aprendizagem.".

Assim, para o Professor $\mathrm{H}, \mathrm{O}$ uso de métodos adequados e uso de tecnologias em sala de aula pode auxiliar e facilitar o trabalho do professor, uma vez que esses se tornam uma necessidade para melhorar a qualidade da aprendizagem dos estudantes. Nesse sentido, Libâneo (2007) afirma que o objetivo das escolas é a garantir a aprendizagem dos estudantes e, para isso, é necessário usar métodos adequados. Para Moreira (2000, p. 2) , "[...] há uma necessidade crescente de conhecimento de informática e novas tecnologias, porém, grande parte das escolas não propicia um ensino voltado a viabilizar, por meio desse conhecimento, a inserção social plena dos estudantes".

E de acordo com Masetto (2000, p.139), "[...] a tecnologia apresentase como meio, como instrumento para colaborar no desenvolvimento do processo de aprendizagem". Entretanto, o autor afirma que o uso de tecnologia tem valor relativo, dependendo do trabalho que é realizado em sala de aula.

Conhecer a realidade do estudante também aparece como fator importante na relação professor e estudante, na opinião dos participantes da pesquisa: "O professor precisa conhecer a realidade de cada estudante e levá-la em conta no seu planejamento, assim poderá contextualizar o currículo; para isso, é preciso conhecer cada indivíduo." (Professor M). Sobre isso, o Professor $G$ afirma que "para ser professor é preciso gostar de gente. Para ser professor é necessário preocupar-se com o aluno em sua totalidade.". 
A fala desses participantes está em sintonia com as ideias de Freire (1996, p. 124), que podem ser expressas por sua afirmação: "o que posso fazer é, na perspectiva progressista em que me acho, ao ensinar-Ihe certo conteúdo, desafiá-lo a que se vá percebendo na e pela própria prática, sujeito capaz de saber". Isso implica conhecer os estudantes.

A contextualização contribui para a aprendizagem dos estudantes, pois a partir dela se pode aproveitar os interesses, conhecimentos e realidades diferentes que possuem, de modo a problematizar e tornar a aprendizagem mais atraente e significativa, na construção de novos saberes, significados e desafios. Sobre isso, Fazenda (1994) afirma que um estudo contextualizado está vinculado a uma forma de aprendizagem, mais dinâmica e integrada com a realidade dos alunos. Por outro lado, Ramos (2008) afirma que problematizar a realidade é descortinar o que cada um tem na cabeça: seus conhecimentos e saberes e identificar o seu nãoconhecimento, as suas faltas. Isso significa, portanto, conhecer os estudantes e só se conhece os estudantes ouvindo-os e dialogando com eles, não o contrário.

Assim, percebe-se também nos depoimentos dos participantes que um ensino de qualidade, com métodos e recursos adequados influencia nos processos de ensino e aprendizagem, melhora o nível de satisfação dos estudantes, influenciando na relação afetiva entre eles e o professor. O fato de o professor conhecer a realidade do estudante favorece uma aproximação entre ambos, o que também contribui para a aprendizagem discente, na visão dos participantes.

\section{CONSIDERAÇÕES FINAIS}

O principal objetivo deste trabalho foi identificar e compreender as concepções de professores da área de Ciências da Natureza e Matemática, ingressantes em um Programa de Pós-Graduação em Educação em Ciências e Matemática, acerca da influência da relação entre professor e estudantes sobre a aprendizagem. 
Após a análise das respostas dos participantes por meio da ATD, percebeu-se que os professores consideram a afetividade na relação professor-estudante como fator fundamental para que ocorra a aprendizagem dos estudantes.

Os resultados da análise permitem a conclusão de que a boa relação entre professor e estudante, por meio de relações afetivas, de atitudes positivas do professor e também de atitudes apresentadas pelos estudantes na sala de aula contribuem para que ocorra aprendizagem. Cabe ressaltar que a maior parte dos professores considera as atitudes dos estudantes em relação à disciplina e sua própria motivação como fator determinante de aprendizado.

A escola constitui um espaço educativo, cuja função principal é possibilitar aos estudantes aprendizagens relevantes, que estão associadas às relações interpessoais, pois o conhecimento se dá na interação entre os sujeitos.

É importante ressaltar que o processo de ensino e aprendizagem provém de uma relação de parceria, na qual professores e estudantes percebem-se acolhidos a partir de seus contextos e experiências, constroem o conhecimento juntos e percebem a importância de que ensinar e aprender são processos que se complementam, o que contribui para a produção de uma relação de sintonia e afinidade.

Fica a proposição para novas investigações, consultando estudantes da Educação Básica sobre o mesmo tema, de modo a complementar o estudo, dando voz a ambos os lados: professor e estudantes.

\section{REFERÊNCIAS}

ALMEIDA, A. R. S. A emoção na sala de aula. 4 ed. Campinas: Papirus, 2004. ANTUNES, C. Professores e Professauros: reflexões sobre a aula e práticas pedagógicas diversas. Petrópolis, RJ: Vozes, 2007.

BOGDAN, R.; BICKLEN, S. K. Investigação qualitativa em educação. Porto, Portugal: Porto Editora, 1994.

CHALITA, G. Educação: a solução está no afeto. 17. ed. São Paulo: Gente, 
2004.

COSENZA, R. M., GUERRA, L. B. Neurociência e Educação: como o cérebro aprende. Porto Alegre: Artes médicas, 2011.

DEMO, P. Educar pela pesquisa. 9. ed. Campinas: Autores Associados, 2011.

DENZIN, N; LINCOLN, Y. Strategies of qualitative inquiry. 4. ed. SAGE, 2012.

FAZENDA, I. (org.) Práticas interdisciplinares na escola. São Paulo: Papirus, 1994.

FERNANDES, A. A inteligência aprisionada. Porto Alegre: Artmed, 1990.

FERREIRA, A. L. ACIOLY-RÉGNIER, N. M. Contribuições de Henri Wallon à relação cognição e afetividade na educação. Educar, Curitiba, n. 36, p. 2138, 2010.

FREIRE, P. Pedagogia do Oprimido. Rio de Janeiro: Paz e Terra, 2005.

GADAMER, H. G. Verdade e método: traços fundamentais de uma hermenêutica filosófica. 10. ed. Petrópolis, RJ: Vozes, 2008

GHEDIN, Evandro; FRANCO, Maria A.S. Questōes de método na construção da pesquisa em educação. 2 ed. São Paulo: Cortez, 2011.

HABERMAS, Jürgen. Conhecimento e interesse. São Paulo: UNESP, 2014.

HEIDEGGER, M. Ser e tempo. 5. ed. Petrópolis, RJ: Vozes, 2006.

LIBÂNEO, J. C. Didática. São Paulo: Cortez, 1994.

LÜDKE, M.; ANDRÉ, M. E.D.A. Pesquisa em educação: abordagens qualitativas. 2.ed. São Paulo: E.P.U., 2013.

MASETTO, M. T. Mediação Pedagógica e uso da tecnologia. Campinas/ SP, Papirus, 2000.

MATURANA, $H$. Emoções e linguagem na educação e na política. Belo Horizonte: UFMG, 1998.

MERLEAU-PONTY, M. Fenomenologia da percepção. São Paulo: Martins Fontes, 1999.

MINAYO, M. C. (org.). Pesquisa Social: teoria, método e criatividade. Petrópolis: Vozes, 1994.

MINAYO, M. C. S. (Org.). Pesquisa social: teoria, método e criatividade. 32. ed. Petrópolis, RJ: Editora Vozes, 2012.

MORAES, R. Uma tempestade de luz: a compreensão possibilitada pela análise textual discursiva. Ciência \& Educação. Bauru. v. 9, n. 2, p.191$211,2003$.

MORAES, R.; GALIAZZI, M. C. Análise textual discursiva. 3. ed. ljuí: Ed. Unijuí, 2013.

MORALES, P. A relação professor-aluno: o que é, como se faz. 2. ed. São 
Paulo: Edições Loyola, 1998.

MORAN, J. M. A educação que desejamos: novos desafios e como chegar lá. Papirus, 2014.

MORIN, E. Os sete saberes necessários à Educação do futuro. 5. ed. São Paulo: Cortez, 2002.

RAMOS, M.G. A importância da problematização no conhecer e no saber em Ciências. In: GALIAZZI, M.C.; AUTH, M.; MORAES, R.: MANCUSO, R. Aprender em rede na educação em Ciências. Porto Alegre: Edipucrs, 2008. p. 57-76.

VYGOTSKY, L. S. A Formação Social da Mente: o desenvolvimento dos processos psicológicos superiores. 3 ed. São Paulo: Martins Fontes, 1994.

VYGOTSKY, L. S. Psicologia pedagógica. Porto Alegre: Artmed, 2003.

WALLON, H. Do acto ao pensamento. Lisboa, Moraes Editores, 1978.

YIN R. Estudo de caso: planejamento e métodos. 4. ed. Porto Alegre: Bookman, 2010.

Recebido em: Fevereiro de 2017 Aceito em: Julho de 2017 